\title{
Shared Mobile Library Collections
}

The use of bookmobiles is proposed for sharing special book collections among cooperating libraries. The advantages of such an arrangement over freighting joint-use collections from institution to institution include: (1) effort involved in packing, shipping, and receiving can be saved; (2) wear and tear on the books resulting from shipment can be reduced; and (3) mobile units can be considered supplemental library floor space.

$I_{1}$

T IS WELL KNOwN that one of the most pressing problems in almost every college is library acquisitions. Compounding this problem is the fact that the need for additional acquisitions has been made more compelling due to increased publication, new dimensions of research and the need to add even more courses to college programs dealing with new areas of study such as the Far East and Latin America.

Colleges have responded to this critical situation by developing various methods for the cooperative acquisition and use of library materials. One additional type of academic cooperation which seems to be both apparent and desirable is the use of mobile library units which could be transported between two or more institutions.

Standard mobile units, such as those currently in use in many public library systems, are as large as $10^{\prime} \times 35^{\prime}$; the cost of these units, including shelving, lighting, air-conditioning, and heating, is approximately $\$ 7,500$ to $\$ 8,000$. It is possible, of course, to employ custom trailer construction which would allow for even larger units. For example, ex-

The author is Associate Professor of Political Science in Florida Presbyterian College, St. Petersburg. pandable units which have a maximum size of $20^{\prime} \times 35^{\prime}$ are available. Also, two of them can be joined together on a location providing a total space of $20^{\prime} \mathrm{x}$ $70^{\prime}$. Additional custom features can provide space for such items as microfilm readers and storage.

It would not be advisable, it seems, to attempt to utilize such mobile holdings for introductory level courses, or courses which are offered at cooperating institutions each semester of each year. Great economy and utility for cooperating institutions could result, however, in using them for courses offered in alternate semesters or alternate years. In order to illustrate in what way these mobile units could be used by cooperating colleges let us assume that colleges A and B decide to offer Chinese history. This would be a two-semester sequence course offered in alternate years. The two institutions would agree to offer them in different years; thus, College A would offer it in the academic year 1967-1968, and College B in 1968-1969. In order to provide the maximum holdings to support and supplement the teaching of the faculty and the learning of the student, the jointly held collection would be placed in a mobile unit, which would be housed on the campus where the course was being offered for both semesters. The 


\section{8 / College b Research Libraries • January 1968}

collection, housed in this unit would be cataloged in the mobile unit, as well as in the catalogs of both institutions. These mobile units, when they are resident on a campus could be used in a variety of ways as a supplement for that college's existing library facilities. The following four methods of use are suggested.

First, the mobile unit could be placed adjacent to the main library. This collection could be made available for a limited number of hours each day, since it would be unlikely that the materials would be used by any student or faculty other than those involved in the course. Thus, limited availability, for purposes of checking out and returning materials would seem acceptable. Also, this would not involve extensive demands on use of library personnel to staff this mobile unit, for only one library assistant would be needed for the hours this unit was open.

Second, in order to assure access to this collection on the same basis as other library holdings and in order not to require additional library personnel to staff the mobile unit on such a basis, the cooperating schools could arrange to have this unit joined physically to their existing libraries. Minor alterations could be made on one of the exterior walls of the stack which would allow the door of the mobile unit to be opened into the stack area. The provision of such a point of access would seem to involve very little construction. If there were at least two continually rotating collections so that each campus would have one of them resident on its campus every year, such an arrangement would be very desirable. Consequently access to the collection would be on the same basis as access to other stack holdings, and all checking in and out of materials would be done at the main desk of the library.

Third, the shelving on which the collection was housed in the mobile unit, could itself be movable so that the col- lection could be wheeled into the main library's regular stack section. In this instance, it would seem quite practical for the college involved to use this vacated unit as an additional room por: classes or seminars, or for ditional study space lost to the library by virtue of their needing space in which to locate this unit's collection. This seems less desirable, since it seems eminently more practical to use the collection in the mobile unit.

Fourth, the collection in the mobile unit could be considered a branch library and could be housed adjacent to the buildings in which the appropriate department was located. The department or division could, therefore, share the costs with the main library for staffing the unit and paying the overhead costs involved.

Some of the benefits proposed in this suggestion duplicate the benefits involved for colleges with shared bloc holdings which can be transported by simple freight transfers, mainly in terms of reduced cost of acquisition. It seems that there are three major additional benefits, however, which accrue from this suggestion which make it more desirable than freight transfers.

First, library staffs would not be faced with the necessity of packing, invoicing, and shipping a bloc collection at the end of any term, or for receiving, inventorying, and shelving such a collection. This seems to be an inordinate demand of time, energy, and involvement on already overworked library staffs.

Second, the collection would not be subjected to the wear and tear resulting from the continual packing and repacking involved in transporting bloc collections by freight. Indeed, in this mobile unit, these collections would be very similar to parts of the permanent collection of the library.

Third, the use of the mobile unit would be economical for the cooperating 
colleges not only in terms of the cost of the collections, but it would also reduce considerably the cost involved for constructing space in which to house this collection. Further, the space constructed to house a collection which is to be moved by freight is vacant when this collection is moved, and, even though it might be utilized for study areas, it is a costly way to provide such an area.

These then are the additional benefits that would seem to result from the use of mobile units. Most important, however is the fact that it provides colleges with a cheaper method of acquiring and housing collections which are needed in areas of study.

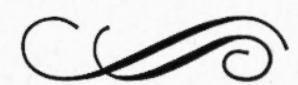

